\title{
Effect of growth differentiation factor-9 C447T and G546A polymorphisms on the outcomes of in vitro fertilization
}

\author{
MONIKA SERDYŃSKA-SZUSTER ${ }^{1}$, PIOTR JĘDRZEJCZAK ${ }^{1}$, KATARZYNA EWA OŻEGOWSKA ${ }^{1}$, \\ HANNA HOŁYSZ ${ }^{2}$, LESZEK PAWELCZYK ${ }^{1}$ and PAWEŁ PIOTR JAGODZIŃSKI ${ }^{3}$
}

\begin{abstract}
${ }^{1}$ Division of Infertility and Reproductive Endocrinology, Department of Gynecology, Obstetrics and Gynecological Oncology;
${ }^{2}$ Department of Clinical Chemistry and Molecular Diagnostics; ${ }^{3}$ Department of Biochemistry and Molecular Biology,

Poznan University of Medical Sciences, 60-781 Poznań, Poland
\end{abstract}

Received October 2, 2015; Accepted February 2, 2016

DOI: $10.3892 / \mathrm{mmr} .2016 .5060$

\begin{abstract}
Single nucleotide polymorphisms (SNPs) in the growth differentiation factor $(G D F)-9$ gene are associated with premature ovarian failure, insufficient ovarian stimulation and a poor in vitro fertilization (IVF) score in women with diminished ovarian reserve. The aim of the present study was to assess the effect of C447T (rs254286) and G546A (rs10491279) SNPs on ovary stimulation response, oocyte quality, fertilization rate and outcome of clinical pregnancy in an infertile population of Polish females $(n=86)$ treated with IVF. The present study also included a group of fertile women $(\mathrm{n}=202)$. The P-trend value, calculated for the GDF-9 C447T transition in infertile women, was statistically significant and were equal to 0.0195. A significant association of the GDF-9 C447T SNP was observed with infertility for the $\mathrm{C} / \mathrm{C}$ vs. $\mathrm{T} / \mathrm{T}+\mathrm{C} / \mathrm{T}$ model $(\mathrm{OR}=2.140 ; 95 \% \mathrm{CI}=1.043-4.393$; $\mathrm{P}=0.0349)$. The GDF-9 G546A SNP was significantly associated with the G/A vs. G/G model with poor ovarian stimulation $(\mathrm{OR}=9.303 ; 95 \% \mathrm{CI}=2.568-33.745 ; \mathrm{P}=0.0008)$ and poor fertilization rate $(\mathrm{OR}=2.981 ; 95 \% \mathrm{CI}=1.033-8.607 ; \mathrm{P}=0.0385)$. For the GDF-9 C447T SNP, a significant association was observed between the $\mathrm{C} / \mathrm{C}+\mathrm{C} / \mathrm{T}$ vs. $\mathrm{T} / \mathrm{T}$ model and a poor ovarian stimulation response $(\mathrm{OR}=15.309 ; 95 \% \mathrm{CI}=0.875-267.83$; $\mathrm{P}=0.0078)$, and a poor fertilization rate $(\mathrm{OR}=4.842 ; 95 \%$ $\mathrm{CI}=1.310-17.901 ; \mathrm{P}=0.0121)$. The present genetic evaluation revealed associations between IVF outcomes and the GDF-9 A546G and C447T SNPs. Additionally, these results indicated that the GDF-9 C447T SNP is a possible candidate genetic risk factor for female infertility in the Polish population.
\end{abstract}

Correspondence to: Dr Paweł Piotr Jagodziński, Department of Biochemistry and Molecular Biology, Poznan University of Medical Sciences, 6 Święcickiego Street, 60-781 Poznań, Poland E-mail: pjagodzi@am.poznan.pl

Key words: infertility, GDF9, polymorphisms

\section{Introduction}

Previous studies have demonstrated that $\sim 17 \%$ of couples are unable to conceive (1). In vitro fertilization (IVF) is an efficient assisted reproductive medical technology that is used to treat infertility. The objective of IVF is a full-term pregnancy and the success of IVF is influenced by several factors (2). One of the essential elements of successful IVF treatment is the number of eggs produced following controlled ovarian hyperstimulation with gonadotropins and GnRH analogues (3). However, poor ovarian responses (PORs) have been demonstrated in $9-24 \%$ of all IVF cases (4). The mechanism of follicular depletion in a POR remains to be fully understood. Some of the causes of POR include ovarian surgery, single ovary, autoimmune diseases, chemotherapy, radiotherapy, cigarette combustion, unknown infertility and diminished ovarian reserve (DOR) (5-12). A DOR is characterized by a reduction in both oocyte quantity and quality, whereby the oocytes produced are unable to be fertilized, therefore, reducing the possibility of a healthy and successful pregnancy in women of childbearing age (13). The occurrence of DOR is associated with aging, premature ovarian failure and menopause $(13,14)$. It is suggested that $\sim 10 \%$ of women suffering from infertility exhibit a DOR $(15,16)$. Infertility and POR are also strongly influenced by genetic background (17).

Several factors regulate follicular growth and depletion. These include bone morphogenetic protein (BMP)-15, anti-Müllerian hormone (AMH), G-protein coupled receptor (GPR)3, newborn ovary homeobox protein and growth differentiation factor (GDF)-9 (18-20). Single nucleotide polymorphisms (SNPs) of these genes are associated with abnormal follicular function and reduced female fertility (21).

GDF-9 contributes to ovarian folliculogenesis as an essential molecule, which controls various granulosa cell processes and ovulation rate. GDF-9 supports proliferation of granulosa cells and the growth of cumulus cells, the halt of follicular apoptosis, and the growth of the oocyte and embryo (22-25).

$G D F-9$ variants are associated with premature ovarian failure (POF), aberrant follicular growth and the loss of oocytes (26-28). In addition, novel SNPs located in GDF-9 have been correlated with insufficient ovarian stimulation and a poor IVF score in women with a DOR (29). The 
aim of the present study was to evaluate the effects of the C447T (rs254286) and G546A (rs10491279) SNPs on ovary stimulation response, oocyte quality, fertilization rate and the outcome of clinical pregnancy in infertile women treated with IVF.

\section{Materials and methods}

Patients. Peripheral blood samples from 88 infertile women treated with an IVF procedure and 202 fertile control women were obtained from the Division of Infertility and Reproductive Endocrinology, University of Medical Sciences (Poznan, Poland). Inclusion criteria for the infertile women included individuals aged $<35$ with a regular menstrual cycle (28 \pm 7 days), a serum concentration of follicle stimulating hormone $(\mathrm{FSH})<12 \mathrm{IU} / \mathrm{ml}$ at the early follicular phase (menstrual cycle day 2-4), an anatomically intact reproductive tract and infertility spanning at least 2 years, despite the desire and attempts to conceive. The exclusion criteria included male factor infertility, body mass index $>25$, irregular menstrual cycle ( $<21$ or $>35$ days), concentration of FSH $>12 \mathrm{IU} / \mathrm{ml}$, diabetes, polycystic ovarian syndrome (PCOS), endocrine disorders, habitual smoking of cigarettes and receiving hormone treatment during the 3 months prior to the present study. The exclusion criteria also included ultrasonography (USG)-determined endometriosis, ovarian cysts with diameter $>3 \mathrm{~mm}$, fibroids and hydrosalpinx.

The fertile women were aged $<35$ and gave birth to a child during the 12 months prior to the present study, with a maximum 12 months of desire for conception. These individuals also exhibited regular menses, an anatomically intact reproductive tract and were without any malignancies, endometriosis, or adenomyosis determined during a cesarean section. The fertile and infertile women were matched by age and were all Caucasians of Polish descent (Table I).

Evaluation of ovarian reserve. The concentration of $\mathrm{FSH}$, $\mathrm{AMH}$ and Inhibin B were determined in the blood plasma at the early follicular phase (days 2-4 of the menstrual cycle) during the 3 months prior to starting the IVF procedure. Two independent researchers determined the antral follicle counts with a diameter of 2-10 mm during a transvaginal ultrasound examination with a frequency of $7.5 \mathrm{MHz}$ using the Hitachi Aloka's Prosound Alpha 7 instrument (Hitachi Aloka, Wallingford, CT, USA).

Controlled hyperstimulation of the ovaries. The IVF technique performed included the standard long protocol of controlled ovarian stimulation. Briefly, the infertile women were treated with a GnRH analogue (Gonapeptyl 0.1; Ferring Pharmaceuticals, Kiel, Germany). This treatment was initiated on day 21 of the menstrual cycle, preceding the hyperstimulation of the ovaries. Pituitary desensitization was determined by the evaluation of luteinizing hormone $(\mathrm{LH})<2 \mathrm{IU} / 1$ and $17 \beta$-estradiol $<50 \mathrm{pg} / \mathrm{ml}$ in the peripheral blood plasma, USG assessment of endometrial thickness $<5 \mathrm{~mm}$ and the lack of an ovarian follicle with a diameter $>10 \mathrm{~mm}$. Next, the women were treated with a subcutaneous injection of gonadotropin Gonal F (Merck Serono, Geneva, Switzerland) and/or Menopur (Ferring
Pharmaceuticals). The dose of these gonadotropins was dependent on the patient response to USG ovary examination and levels of $17 \beta$-estradiol in the peripheral blood plasma. This evaluation commenced from the fifth day of stimulation and ended at the time of human chorionic gonadotropin (hCG) administration. When at least three leading follicles reached $17 \mathrm{~mm}$ in diameter, $250 \mu \mathrm{g} \mathrm{hCG}$ (Merck Serono Europe) was used. Premature luteinizing was excluded by assessment of progesterone levels $(<1.5 \mathrm{ng} / \mathrm{ml})$. Oocyte retrieval was performed under transvaginal USG guidance $36 \mathrm{~h}$ following hCG injection. Oocytes were classified as mature if they were in metaphase II (MII) or immature if they were in metaphase I (MI), or the germinal vesicle stage. After 16-18 h of fertilization intracytoplasmic sperm injection, the quality of the embryos was assessed by the presence of two pronuclei, according to the Alpha Scientists of the Reproductive Medicine and ESHRE Special Interest Group of Embryology (30). After fertilization (72 h) the embryos were transferred into the patient. Supernumerary embryos were evaluated on the fifth day of culture and subjected to a process of vitrification freezing. The patients with embryos were vaginally supplemented with $600 \mathrm{mg}$ progesterone Luteina daily (Adamed, Pieńków, Poland). Pregnancy was confirmed 14 days after embryo transfer using hCG levels in the peripheral blood plasma. Clinical pregnancies were determined by USG examination during the sixth week of pregnancy. POR was designated as the retrieval of $\leq 3$ oocytes and was determined at cycle cancellation. Oocytes of good quality were defined as $\geq 75 \%$ oocytes in metaphase II. The presence of two pronuclei was considered to indicate fertilization. Good fertilization rate was considered as at least $50 \%$ fertilization rate was achieved on the third day. Informed consent was obtained in writing from all individuals. The Local Ethical Committee of Poznan University of Medical Sciences approved the procedures used in the present study.

Genotyping. DNA was isolated from the peripheral leucocytes using a salting out procedure (31). A DNA fragment (509 bp) covering the fragment of intron 1 (final $57 \mathrm{bp}$ ) and a fragment of exon 2 (first 452 bp) of the GDF-9 gene was amplified using the primers, 5'-CTGCCTGTTGTGTTG ACTGA-3' and 5'-ATAGTGAAGGGA ATACCAGC-3'. The GDF-9 C447T (rs254286) and G546A (rs10491279) polymorphisms were subsequently determined by a Sanger sequencing analysis at the Laboratory of DNA Sequencing and Oligonucleotides Synthesis, Institute of Biochemistry and Biophysics, The Polish Academy of Science (Warsaw, Poland). The results of sequencing were evaluated using FinchTV v.1.4.0 software (Geospiza, Inc., Seattle, WA, USA).

Statistical analysis. For each SNP, the Hardy-Weinberg equilibrium (HWE) was assessed using Pearson's goodness-of-fit $\chi^{2}$ statistic. The association between the selected SNPs and the analyzed groups was evaluated using the Cochran-Armitage P-trend test $\left(\mathrm{P}_{\text {trend }}\right), \chi^{2}$ or Fisher tests. The Odds ratios $(\mathrm{OR})$ and associated $95 \%$ confidence intervals (CI) were also assessed. The data were analyzed using recessive and dominant inheritance models. $\mathrm{P}<0.05$ was considered to indicate a statistically significant difference. Statistical analysis was performed using Statistica version 10.2011 (StatSoft, Inc., Tulsa, OK, USA). 
Table I. Clinical characteristics of infertile and fertile females.

\begin{tabular}{lcc}
\hline Characteristic & Infertile & Fertile \\
\hline Number & 88 & 202 \\
Median age, years (range) & $31(23-34)$ & $31(22-34)$ \\
Parity & NA & $1(1-2)$ \\
Duration of infertility, years (range) & $3(1-6)$ & NA \\
\hline
\end{tabular}

NA, not applicable.

Table II. Distribution of growth differentiation factor-9 G546A (rs10491279) single nucleotide polymorphism in fertile (n=202) and various subgroups of infertile females $(n=88)$ treated with IVF.

\begin{tabular}{|c|c|c|c|c|}
\hline \multirow[b]{2}{*}{ Patient/subgroup } & \multicolumn{2}{|c|}{ Genotype number (\%) } & \multirow[b]{2}{*}{ Adjusted Odds ratio $(95 \% \mathrm{CI})^{\mathrm{b}}$} & \multirow[b]{2}{*}{ P-value } \\
\hline & $\mathrm{G} / \mathrm{G}$ & $\mathrm{G} / \mathrm{A}$ & & \\
\hline Fertile females & $165(81.7)$ & $37(18.3)$ & $1.228(0.660-2.284)^{\mathrm{c}}$ & $0.516^{\mathrm{a}}$ \\
\hline \multicolumn{5}{|c|}{ Infertile females treated with IVF } \\
\hline Good responders & $64(72.7)$ & $11(12.5)$ & \multirow{2}{*}{$9.303(2.568-33.745)^{d}$} & \multirow{2}{*}{$0.0008^{b}$} \\
\hline Poor responders & $5(5.7)$ & $8(9.1)$ & & \\
\hline Good quality oocytes & $47(53.4)$ & $10(11.4)$ & \multirow{2}{*}{$1.923(0.684-5.404)^{\mathrm{e}}$} & \multirow{2}{*}{$0.211^{\mathrm{a}}$} \\
\hline Poor quality oocytes & $22(25.0)$ & $9(10.2)$ & & \\
\hline Good fertilization rate & $53(60.2)$ & $10(11.4)$ & \multirow{2}{*}{$2.981(1.033-8.607)^{f}$} & \multirow{2}{*}{$0.0385^{\mathrm{a}}$} \\
\hline Poor fertilization rate & $16(18.2)$ & $9(10.2)$ & & \\
\hline Positive pregnancy & $38(43.2)$ & $10(11.4)$ & \multirow{2}{*}{$1.103(0.399-3.054)^{\mathrm{g}}$} & \multirow{2}{*}{$0.850^{\mathrm{a}}$} \\
\hline Negative pregnancy & $31(35.2)$ & $9(10.2)$ & & \\
\hline
\end{tabular}

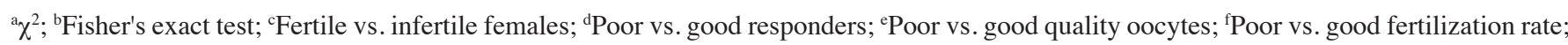
${ }^{g}$ Negative vs. positive pregnancy. Statistically significant data are highlighted in bold. No A/A genotype was identified in infertile or fertile females. Good responders $\geq 4$ oocytes; good quality oocytes $\geq 75 \%$ oocytes in metaphase II; good fertilization rate $\geq 50 \%$ fertilization at third day; IVF, in vitro fertilization; CI, confidence intervals.

\section{Results}

Contribution of GDF-9 G546A (rs10491279) and C447T (rs254286) to infertility. The values for the $\chi^{2}$ test of HWE were equal to 0.358 and 0.525 for the $G D F-9$ G546A SNP and 0.414 and 0.935 for the GDF-9 C447T SNP in the infertile and fertile women, respectively. The frequency of genotypes and results of statistical analyses are shown in Tables II and III. No association between the GDF-9 G546A SNP was observed with infertility in the dominant (G/A vs. G/G) inheritance model $(\mathrm{OR}=1.228 ; 95 \% \mathrm{CI}=0.660-2.284 ; \mathrm{P}=0.516)$. However, the P-trend value of 0.0195 , calculated for the GDF-9 C447T transition, was statistically significant. A contribution of the GDF-9 C447T SNP was confirmed for infertility in the recessive $(\mathrm{C} / \mathrm{C}$ vs. $\mathrm{T} / \mathrm{T}+\mathrm{C} / \mathrm{T})$ inheritance model $(\mathrm{OR}=2.140 ; 95 \%$ $\mathrm{CI}=1.043-4.393 ; \mathrm{P}=0.0349)$. No association was observed between the GDF-9 C447T SNP and infertility in the dominative $(\mathrm{C} / \mathrm{C}+\mathrm{C} / \mathrm{T}$ vs. $\mathrm{T} / \mathrm{T})$ inheritance model $(\mathrm{OR}=1.608 ; 95 \%$ $\mathrm{CI}=0.944-2.740 ; \mathrm{P}=0.0791$ ).

Contribution of GDF-9 G546A (rs10491279) to ovary stimulation response, oocyte quality, fertilization rate and pregnancy outcome. The genotype distribution for good/poor responders, good/poor quality oocytes, good/poor fertilization rates and the outcome of clinical pregnancy for the GDF-9 G546A SNP are shown in Table II. The A/A genotype was not identified in infertile and fertile women. A significant association between the dominant (G/A vs. G/G) inheritance model and the group of poor ovary stimulation responders $(\mathrm{OR}=9.303,95 \% \mathrm{CI}=2.568-33.745$, $\mathrm{P}=0.0008$ ) was demonstrated. An association was also demonstrated between the $G D F-9 \mathrm{G} 546 \mathrm{~A}$ SNP with a poor fertilization rates for $\mathrm{G} / \mathrm{A}$ vs. $\mathrm{G} / \mathrm{G}(\mathrm{OR}=2.981$; 95\% $\mathrm{CI}=1.033-8.607$; $\mathrm{P}=0.0385)$. However, the GDF-9 G546A SNP revealed no influence on poor quality oocytes $(\mathrm{OR}=1.923$; $95 \% \mathrm{CI}=0.684-5.404$; $\mathrm{P}=0.211)$ and outcome of clinical pregnancy $(\mathrm{OR}=1.103 ; 95 \%$ $\mathrm{CI}=0.399-3.054 ; \mathrm{P}=0.850)$.

Contribution of GDF-9 C447T (rs254286) to ovary stimulation response, oocyte quality, fertilization rate and pregnancy outcome. The genotype distribution for good/poor responders, good/poor quality oocytes, good/poor fertilization rates and the outcome of clinical pregnancy for the GDF-9 C447T SNP are shown in Table III. For poor ovary stimulation responders, a P-trend of 0.256 , calculated for the GDF-9 C447T 
Table III. Distribution of growth differentiation factor-9 C447T (rs254286) single nucleotide polymorphism in fertile ( $\mathrm{n}=202$ ) and various subgroups of infertile females $(n=88)$ treated with IVF.

\begin{tabular}{|c|c|c|c|c|c|c|}
\hline \multirow[b]{2}{*}{ Patient/subgroup } & \multicolumn{3}{|c|}{ Genotype number (\%) } & \multirow[b]{2}{*}{ Adjusted Odds ratio $(95 \% \mathrm{CI})^{\mathrm{b}}$} & \multirow[b]{2}{*}{ P-value } & \multirow[b]{2}{*}{ P-trend } \\
\hline & $\mathrm{T} / \mathrm{T}$ & $\mathrm{T} / \mathrm{C}$ & $\mathrm{C} / \mathrm{C}$ & & & \\
\hline \multirow[t]{2}{*}{ Fertile females } & 84 (41.6) & $99(49.0)$ & $19(9.4)$ & $2.140(1.043-4.393)^{\mathrm{a}, \mathrm{e}}$ & $0.0349^{c}$ & 0.0195 \\
\hline & & & & $1.608(0.944-2.740)^{\mathrm{b}, \mathrm{e}}$ & $0.0791^{\mathrm{c}}$ & \\
\hline \multirow{2}{*}{\multicolumn{7}{|c|}{$\begin{array}{l}\text { Infertile females } \\
\text { treated with IVF }\end{array}$}} \\
\hline & & & & & & \\
\hline Good responders & $27(30.7)$ & $33(37.5)$ & $15(17.1)$ & $0.333(0.0401-2.770)^{\mathrm{a}, \mathrm{f}}$ & $0.448^{\mathrm{d}}$ & \multirow{2}{*}{0.256} \\
\hline Poor responders & $0(0.0)$ & $12(13.6)$ & $1(1.1)$ & $15.309(0.875-267.83)^{b, f}$ & $0.0078^{d}$ & \\
\hline Good quality oocytes & $17(19.3)$ & $28(31.8)$ & $12(13.6)$ & $0.556(0.163-1.898)^{\mathrm{a}, \mathrm{g}}$ & $0.400^{\mathrm{d}}$ & \multirow{2}{*}{0.491} \\
\hline Poor quality oocytes & $10(11.4)$ & $17(19.3)$ & $4(4.6)$ & $0.893(0.348-2.292)^{\mathrm{b} . \mathrm{g}}$ & $0.813^{\mathrm{c}}$ & \\
\hline Good fertilization rate & $24(27.3)$ & $25(28.4)$ & $13(14.8)$ & $0.492(0.128-1.896)^{\mathrm{a}, \mathrm{h}}$ & $0.375^{\mathrm{d}}$ & \multirow{2}{*}{0.270} \\
\hline Poor fertilization rate & $3(3.4)$ & $20(22.7)$ & $3(3.4)$ & $4.842(1.310-17.901)^{\mathrm{b}, \mathrm{h}}$ & $0.0121^{\mathrm{d}}$ & \\
\hline Positive pregnancy & $14(15.9)$ & $24(27.3)$ & $10(11.4)$ & $0.671(0.220-2.041)^{\mathrm{a}, \mathrm{gg}}$ & $0.584^{\mathrm{d}}$ & \multirow{2}{*}{0.534} \\
\hline Negative pregnancy & $13(14.8)$ & $21(23.9)$ & $6(6.8)$ & $0.855(0.345-2.122)^{\mathrm{b}, \mathrm{g}}$ & $0.736^{\mathrm{c}}$ & \\
\hline
\end{tabular}

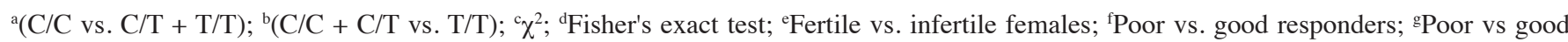
quality oocytes; ' $\mathrm{P}$ Poor vs. good fertilization rate; ${ }^{\mathrm{N}}$ Negative vs. positive pregnancy. Statistically significant data are highlighted in bold. Good responders $\geq 4$ oocytes; good quality oocytes $\geq 75 \%$ oocytes in metaphase II; good fertilization rate $\geq 50 \%$ fertilization at third day; IVF, in vitro fertilization; CI, confidence intervals.

SNP, was not statistically significant. However, a significant association with poor ovarian stimulation responders in the dominant $(\mathrm{C} / \mathrm{C}+\mathrm{C} / \mathrm{T}$ vs. $\mathrm{T} / \mathrm{T})$ inheritance model $(\mathrm{OR}=15.309 ; 95 \% \mathrm{CI}=0.875-267.83 ; \mathrm{P}=0.0078)$ was revealed. For the poor fertilization rate, a P-trend of 0.270 , calculated for the GDF-9 C447T SNP, was not statistically significant. However, a significant association was observed with a poor fertilization rate in the dominant $(\mathrm{C} / \mathrm{C}+\mathrm{C} / \mathrm{T}$ vs. $\mathrm{T} / \mathrm{T})$ inheritance model $(\mathrm{OR}=4.842 ; 95 \% \mathrm{CI}=1.310-17.901 ; \mathrm{P}=0.0121)$. No significant contribution of the GDF-9 C447T SNP was revealed in the recessive $(\mathrm{C} / \mathrm{C}$ vs. $\mathrm{C} / \mathrm{T}+\mathrm{T} / \mathrm{T})$ inheritance model to poor ovarian stimulationresponse $(\mathrm{OR}=0.333 ; 95 \% \mathrm{CI}=0.0401-2.770 ; \mathrm{P}=0.448)$ or a poor fertilization rate $(\mathrm{OR}=0.492 ; 95 \% \mathrm{CI}=0.128-1.896$; $\mathrm{P}=0.375)$. Additionally, no association of the GDF-9 C447T SNP was demonstrated with poor quality oocytes $\left(\mathrm{P}_{\text {trend }}=0.491\right)$, for the recessive $(\mathrm{C} / \mathrm{C}$ vs. $\mathrm{C} / \mathrm{T}+\mathrm{T} / \mathrm{T})$ inheritance model $(\mathrm{OR}=0.556 ; 95 \% \mathrm{CI}=0.163-1.898 ; \mathrm{P}=0.400)$ and for the dominant $(\mathrm{C} / \mathrm{C}+\mathrm{C} / \mathrm{T}$ vs. $\mathrm{T} / \mathrm{T})$ inheritance model $(\mathrm{OR}=0.893 ; 95 \% \mathrm{CI}=0.348-2.292 ; \mathrm{P}=0.813)$. In addition, no involvement of the C447T SNP was detected in the outcome of clinical pregnancies $\left(\mathrm{P}_{\text {trend }}=0.534\right)$ for the recessive $(\mathrm{C} / \mathrm{C}$ vs. $\mathrm{C} / \mathrm{T}+\mathrm{T} / \mathrm{T})$ inheritance model $(\mathrm{OR}=0.671 ; 95 \% \mathrm{CI}=0.220-2.041$; $\mathrm{P}=0.584)$ or for the dominant $(\mathrm{C} / \mathrm{C}+\mathrm{C} / \mathrm{T}$ vs. $\mathrm{T} / \mathrm{T})$ inheritance model $(\mathrm{OR}=0.855 ; 95 \% \mathrm{CI}=0.345-2.122 ; \mathrm{P}=0.736)$.

\section{Discussion}

In addition to the various intra- and extra-ovarian components, which contribute to the growth of follicles, including FSH, LH and estrogen, paracrine factors produced by oocytes appear to be crucial to the growth of follicles (18). GDF-9, in combination with BMP6, BMP15 and fibroblast growth factors, belong to a transforming growth factor $s \beta$ superfamily of proteins, which are the mammalian oocyte-derived paracrine factors (18). These molecules control the function and differentiation of somatic granulosa cells and the growth of the ovarian follicle (18). The essential role of GDF-9 in folliculogenesis and fertility has been well documented in a murine model study by Dong et al (32). The authors observed that GDF-9-knockout mice were infertile, exhibiting smaller ovaries compared with the wild-type mice. These mice also lacked normal follicles beyond the primary follicle and no theca cells. The oocytes failed cross normal meiosis in vitro. The serum of GDF-9-knockout mice exhibited increased levels of FSH and LH, which is characteristic of hypergonadotropism and hypogonadism (32). Additionally, the synergistic role of GDF-9 and BMP15 on the growth and functions of granulosa cells and follicles has been demonstrated in murine and sheep models (33-35). Additionally, the crucial role of GDF-9 in folliculogenesis was confirmed in a previous study with Bmp15 $15^{-/}$mice, which displayed a relatively mild phenotype until an additional deletion in one allele of the GDF-9 gene, which lead to severe infertility $(33,34)$. Therefore, genetic variants of GDF-9 may effect infertility, as well as IVF outcomes.

The present study revealed that the $G D F-9546$ G/A heterozygous genotype and the GDF-9 $447(\mathrm{CC}+\mathrm{C} / \mathrm{T})$ genotype were significantly associated with poor ovarian stimulation response and a poor fertilization rate in infertile women treated with IVF.

Wang etal (29) demonstrated that the GDF-9 G546A polymorphism is associated with a poor ovarian response and poor IVF outcomes, as evidenced by a poor fertilization rate, poor oocyte and embryo quality, and a low pregnancy rate in a population of Chinese women with DOR (29). However, this previous study failed to identify the effect of the GDF-9 C447T SNP on ovarian response and IVF outcomes (29). These 
discrepancies between the present study and the previous study may be due to patient differences in the causes of infertility or to differences in distinct genetic heterogeneity interactions with disparate environmental factors.

Previously, Ma etal (36) found that the GDF-9 546A gene variant is a risk factor for POF in the Chinese Hui population. In addition, the elevated frequencies of certain GDF-9 heterozygous variants, including the C447T SNP, have been identified in European, Caucasian and Asian women with POF failure $(26,28,37,38)$, however, not in New Zealander or Japanese woman $(27,38)$. A tandem duplication of 475 bp in the GDF-9 promoter was previously identified as a causative factor of primary ovarian insufficiency (39). The GDF-9 variants have also been associated with the risk of PCOS (40) and have been associated with hirsutism scores and parity in patients with PCOS (41).

The present study identified that the GDF-9 C447T (rs254286) SNP was a possible candidate genetic risk factor for female infertility. This SNP may be associated with certain unidentified missense mutations, resulting in abnormal protein expression of GDF-9 and loss of GDF-9 function. Previously, it was reported that GDF-9 forms a heterodimer with BMP15, which is 10-3,000-fold more biologically active compared with the homodimers of these two proteins (42). Therefore, a missense mutation, either in $G D F-9$ or $B M P 15$, may result in the destabilization of this complex, causing female infertility.

The present genetic analysis confirmed the GDF-9 A546G SNP as a genetic factor associated with a poor ovarian stimulation response and a poor fertilization rate in infertile women treated with IVF. Additionally, the present study is the first, to the best of our knowledge, to identify the GDF-9 C447T (rs254286) SNP as a possible candidate genetic risk factor for female infertility and to associate this SNP with a poor ovarian stimulation response and a poor fertilization rate in infertile women treated with IVF. However, the present study is limited by a low statistical power, therefore the conclusions require confirmation in future studies with other larger independent ethnicities.

\section{Acknowledgments}

The present study was supported by a grant from the National Science Centre (no. NN407297540).

\section{References}

1. Farquhar C, Rishworth JR, Brown J, Nelen WL and Marjoribanks J: Assisted reproductive technology: An overview of Cochrane Reviews. Cochrane Database Syst Rev 7: CD010537, 2015.

2. Broekmans FJ, Kwee J, Hendriks DJ, Mol BW and Lambalk CB: A systematic review of tests predicting ovarian reserve and IVF outcome. Hum Reprod Update 12: 685-718, 2006.

3. van Loendersloot L, Repping S, Bossuyt PM, van der Veen F and van Wely M: Prediction models in in vitro fertilization; where are we? A mini review. J Adv Res 5: 295-301, 2014.

4. Sunkara SK, Coomarasamy A, Arlt W and Bhattacharya S: Should androgen supplementation be used for poor ovarian response in IVF? Hum Reprod 27: 637-640, 2012.

5. Fritz MA and Speroff L (eds): Clinical gynecologic endocrinology and infertility. 8th edition. Wolters Kluwer Health/Lippincott Williams \& Wilkins, Philadelphia, 2011.

6. Soto N, Iñiguez G, López P, Larenas G, Mujica V, Rey RA and Codner E: Anti-Mullerian hormone and inhibin B levels as markers of premature ovarian aging and transition to menopause in type 1 diabetes mellitus. Hum Reprod 24: 2838-2844, 2009
7. Benaglia L, Somigliana E,w Vighi V, Ragni G, Vercellini P and Fedele L: Rate of severe ovarian damage following surgery for endometriomas. Hum Reprod 25: 678-682, 2010.

8. Raffi F, Metwally M and Amer S: The impact of excision of ovarian endometrioma on ovarian reserve: A systematic review and meta-analysis. J Clin Endocrinol Metab 97: 3146-3154, 2012.

9. Chang HH, Chen MJ, Lu MY, Chern JP, Lu CY, Yang YL, Jou ST, Lin DT, Yang YS and Lin KH: Iron overload is associated with low anti-müllerian hormone in women with transfusion-dependent $\beta$-thalassaemia. BJOG 118: 825-831, 2011.

10. Hehenkamp WJ, Volkers NA, Broekmans FJ, de Jong FH, Themmen AP, Birnie E, Reekers JA and Ankum WM: Loss of ovarian reserve after uterine artery embolization: A randomized comparison with hysterectomy. Hum Reprod 22: 1996-2005, 2007.

11. Tropeano G, Di Stasi C, Amoroso S, Gualano MR, Bonomo L and Scambia G: Long-term effects of uterine fibroid embolization on ovarian reserve: A prospective cohort study. Fertil Steril 94: 2296-2300, 2010.

12. De Vos M, Devroey P and Fauser BC: Primary ovarian insufficiency. Lancet 376: 911-921, 2010.

13. Gurtcheff SE and Klein NA: Diminished ovarian reserve and infertility. Clin Obstet Gynecol 54: 666-674, 2011.

14. Lawson R, El-Toukhy T, Kassab A, Taylor A, Braude P, Parsons J and Seed P: Poor response to ovulation induction is a stronger predictor of early menopause than elevated basal FSH: A life table analysis. Hum Reprod 18: 527-533, 2003.

15. Leonardi MR, Hofmann GE, Illions EH, Neal GS and Navot D: A prospective evaluation of clomiphene citrate challenge test screening of the general infertility population Obstet Gynecol 82: 539-544, 1993.

16. May-Panloup P, Ferré-L'Hôtellier V, Morinière C, Marcaillou C, Lemerle S, Malinge MC, Coutolleau A, Lucas N, Reynier P, Descamps P and Guardiola P: Molecular characterization of corona radiata cells from patients with diminished ovarian reserve using microarray and microfluidic-based gene expression profiling. Hum Reprod 27: 829-843, 2012.

17. Lledo B, Ortiz JA, Llacer J and Bernabeu R: Pharmacogenetics of ovarian response. Pharmacogenomics 15: 885-893, 2014.

18. Juengel JL and McNatty KP: The role of proteins of the transforming growth factor-beta superfamily in the intraovarian regulation of follicular development. Hum Reprod Update 11: 143-160, 2005.

19. Mehlmann LM: Stops and starts in mammalian oocytes: Recent advances in understanding the regulation of meiotic arrest and oocyte maturation. Reproduction 130: 791-799, 2005.

20. Pangas SA and Rajkovic A: Transcriptional regulation of early oogenesis: In search of masters. Hum Reprod Update 12: 65-76, 2006.

21. Greene AD, Patounakis G and Segars JH: Genetic associations with diminished ovarian reserve: A systematic review of the literature. J Assist Reprod Genet 31: 935-946, 2014.

22. Vitt UA, Hayashi M, Klein C and Hsueh AJ: Growth differentiation factor-9 stimulates proliferation but suppresses the follicle-stimulating hormone-induced differentiation of cultured granulosa cells from small antral and preovulatory rat follicles. Biol Reprod 62: 370-377, 2000.

23. Yan C, Wang P, DeMayo J, DeMayo FJ, Elvin JA, Carino C, Prasad SV, Skinner SS, Dunbar BS, Dube JL, et al: Synergistic roles of bone morphogenetic protein 15 and growth differentiation factor 9 in ovarian function. Mol Endocrinol 15: 854-866, 2001.

24. Orisaka M, Orisaka S, Jiang JY, Craig J, Wang Y, Kotsuji F and Tsang BK: Growth differentiation factor 9 is antiapoptotic during follicular development from preantral to early antral stage. Mol Endocrinol 20: 2456-2468, 2006.

25. Yeo CX, Gilchrist RB, Thompson JG and Lane M: Exogenous growth differentiation factor 9 in oocyte maturation media enhances subsequent embryo development and fetal viability in mice. Hum Reprod 23: 67-73, 2008.

26. Laissue P, Christin-Maitre S, Touraine P, Kuttenn F, Ritvos O, Aittomaki K, Bourcigaux N, Jacquesson L, Bouchard P, Frydman R, et al: Mutations and sequence variants in GDF-9 and BMP15 in patients with premature ovarian failure. Eur J Endocrinol 154: 739-744, 2006.

27. Chand AL, Ponnampalam AP, Harris SE, Winship IM and Shelling AN: Mutational analysis of BMP15 and GDF-9 as candidate genes for premature ovarian failure. Fertil Steril 86: 1009-1012, 2006. 
28. Kovanci E, Rohozinski J, Simpson JL, Heard MJ, Bishop CE and Carson SA: Growth differentiating factor-9 mutations may be associated with premature ovarian failure. Fertil Steril 87: 143-146, 2007.

29. Wang TT, Wu YT, Dong MY, Sheng JZ, Leung PC and Huang HF: G546A polymorphism of growth differentiation factor-9 contributes to the poor outcome of ovarian stimulation in women with diminished ovarian reserve. Fertil Steril 94: 2490-2492, 2010.

30. Alpha Scientists in Reproductive Medicine and ESHRE Special Interest Group of Embryology: The Istanbul consensus workshop on embryo assessment: Proceedings of an expert meeting. Hum Reprod 26: 1270-1283, 2011.

31. Aljanabi SM and Martinez I: Universal and rapid salt-extraction of high quality genomic DNA for PCR-based techniques. Nucleic Acids Res 25: 4692-4693, 1997.

32. Dong J, Albertini DF, Nishimori K, Kumar TR, Lu N and Matzuk MM: Growth differentiation factor-9 is required during early ovarian folliculogenesis. Nature 383: 531-535, 1996.

33. Yan C, Wang P, DeMayo J, DeMayo FJ, Elvin JA, Carino C, Prasad SV, Skinner SS, Dunbar BS, Dube JL, et al: Synergistic roles of bone morphogenetic protein 15 and growth differentiation factor 9 in ovarian function. Molecular Endocrinology 15: 854-866, 2001.

34. Su YQ, Wu X, O'Brien MJ, Pendola FL, Denegre JN, Matzuk MM and Eppig JJ: Synergistic roles of BMP15 and GDF-9 in the development and function of the oocyte-cumulus cell complex in mice: Genetic evidence for an oocyte-granulosa cell regulatory loop. Dev Biol 276: 64-73, 2004.

35. Liao WX, Moore RK, Otsuka F and Shimasaki S: Effect of intracellular interactions on the processing and secretion of bone morphogenetic protein-15 (BMP-15) and growth and differentiation factor-9. Implication of the aberrant ovarian phenotype of BMP-15 mutant sheep. J Biol Chem 278: 3713-3719, 2003.
36. Ma L, Chen Y, Mei S, Liu C, Ma X, Li Y, Jiang Y, Ha L and $\mathrm{Xu} \mathrm{X}$ : Single nucleotide polymorphisms in premature ovarian failure-associated genes in a Chinese Hui population. Mol Med Rep 12: 2529-2538, 2015.

37. Dixit H, Rao LK, Padmalatha V, Kanakavalli M, Deenadayal M, Gupta N, Chakravarty B and Singh L: Mutational screening of the coding region of growth differentiation factor 9 gene in Indian women with ovarian failure. Menopause 12: 749-754, 2005.

38. Takebayashi K, Takakura K, Wang H, Kimura F, Kasahara K and Noda Y: Mutation analysis of the growth differentiation factor-9 and-9B genes in patients with premature ovarian failure and polycystic ovary syndrome. Fertil Steril 74: 976-979, 2000.

39. Norling A, Hirschberg AL, Rodriguez-Wallberg KA, Iwarsson E, Wedell A and Barbaro M: Identification of a duplication within the GDF-9 gene and novel candidate genes for primary ovarian insufficiency (POI) by a customized high-resolution array comparative genomic hybridization platform. Hum Reprod 29 1818-1827, 2014

40. Wang B, Zhou S, Wang J, Liu J, Ni F, Yan J, Mu Y, Cao Y and Ma X: Identification of novel missense mutations of GDF-9 in Chinese women with polycystic ovary syndrome. Reprod Biomed Online 21: 344-348, 2010.

41. Sproul K, Jones MR, Mathur R, Azziz R and Goodarzi MO Association study of four key folliculogenesis genes in polycystic ovary syndrome. BJOG 117: 756-760, 2010.

42. Peng J, Li Q, Wigglesworth K, Rangarajan A, Kattamuri C, Peterson RT, Eppig JJ, Thompson TB and Matzuk MM: Growth differentiation factor 9: Bone morphogenetic protein 15 heterodimers are potent regulators of ovarian functions. Proc Natl Acad Sci USA 110: E776-E785, 2013. 